\title{
Assessment the function of trees as a landscape elements: Case study at Melaka waterfront
}

\begin{abstract}
In many waterfront developments, particularly in the Heritage \& cultural waterfront, most of developments were abandoned. Supposedly vegetation arrangement at waterfront has designed to be a great function for people living, working, shopping, sharing, walking and motoring in and through the townscape. This paper examine on trees as a landscape element at the local cultural \& heritage waterfront as a result to understand about the function of trees in role to enhance the characteristic of places. Hence, direct observation has been used specifically in this study. The observation was conducted by some evidence such as picture observation, news, magazine and interview. This outcome can be helpful for the developer, policy makers and master planner to facilitate in documenting the function of the trees in environment development, as well as help designer and city planners to have a deeper perspective of trees perceptions and opinions in tropical climate.
\end{abstract}

Keyword: Heritage \& cultural waterfront; Function of tree in design; Landscape element 